\title{
Learning Algebra through Mathmagic and Geometry by using Animations
}

\section{Belajar Aljabar melalui Mathmagic dan Geometri menggunakan Animasi}

\author{
Irvandi Gorby Pasangka*, Jusrry Rosalina Pahnael, Ganesha Lapenangga Putra, \& Yoseph Sugi \\ Universitas Nusa Cendana, Penfui, Kupang 85001, Indonesia
}

\begin{abstract}
Mathematics is a basic science that need to be learned at the levels of elementary school, middle school and high school and even at the tertiary level. However, there are still many students who have difficulty in learning mathematics, this is evidenced by their low test scores, one of which is the mathematics test scores. Regarding to these problems, an activity was carried out with the aim of assisting students in understanding mathematics, specifically algebraic and geometric materials for junior high school students, by providing material as attractive as possible so that students become interested and motivated in learning mathematics. The provision of material was carried out in 3 sessions, namely: 1) Delivering algebraic material through mathmagic, 2) Delivering geometric material through animation, 3) Providing motivation about the importance of learning mathematics. Based on the results of this implementation, it can be found that the participants are able to understand and enjoy the learning process with the material presented by the teacher, this can be seen from the activities of the participants during the activity.
\end{abstract}

\begin{abstract}
Abstrak
Matematika merupakan ilmu dasar yang wajib kita pelajari di tingkat SD, SMP, SMA bahkan perguruan tinggi, namun pada kenyataannya, siswa-siswi masih sulit dalam mempelajari matematika, ini dibuktikan dari rendahnya nilai ujian mereka, salah satunya nilai ujian nasional matematika. Berdasarkan masalah ini, kegiatan ini ditujukan untuk membantu siswa-siswi dalam memahami matematika khususnya materi aljabar dan geometri untuk siswa-siswi SMP, yaitu dengan cara memberikan materi semenarik mungkin sehingga para siswa menjadi suka dan termotivasi dalam belajar matematika. Pemberian materi dilakukan dalam 3 sesi yaitu: 1) Pemberian materi aljabar melalui mathmagic, 2) Pemberian materi geometri melalui animasi, 3) Pemberian motivasi tentang pentingnya belajar matematika. Berdasarkan hasil pelaksanaan yang dilakukan, dapat diketahui bahwa para peserta dapat menangkap dan menikmati proses pemberian materi yang diberikan, hal ini terlihat dari keaktifan para peserta selama kegiatan.
\end{abstract}

(C) 2020 Author(s).

Keywords: Algebra, Geometry, Mathmagic.

\section{Pendahuluan}

Matematika merupakan salah satu pelajaran/bidang ilmu yang tidak pernah lepas dari kehidupan manusia. Mulai dari Sekolah Dasar (SD) hingga Sekolah Menengah Atas (SMA) pasti selalu ditemui pelajaran Matematika, bahkan di perguruan tinggi dalam beberapa jurusan tetap adanya mata kuliah Matematika.

\footnotetext{
* Corresponding author:

E-mail address: xxxx@xxxxxx.edu (Name of First Author)
} 
Banyak orang yang tidak menyukai pelajaran Matematika, terutama siswa-siswi di SD, SMP, dan SMA, namun masih banyak guru yang belum maksimal mencari upaya agar keadaan demikian dapat berkurang atau bahkan berubah. Padahal pelajaran ini benar-benar berguna bagi kehidupan kita sehari hari, contohnya adalah saat kita menghitung uang yang kita miliki, saat kita berbelanja kita juga harus mengetahui total harga dari barang-barang yang akan kita beli agar bias terhindar dari penipuan.

Matematika adalah kunci dari semua pelajaran Sains, Kimia, Fisika, maupun Ekonomi dan Akuntansi karena pelajaran tersebut tidak akan dapat kita pahami tanpa mempelajari terlebih dahulu dasarnya yaitu matematika. Karena itu banyak orang tua yang ingin anak - anaknya untuk bisa pandai dalam matematika, maka sebisa mungkin kita harus mananamkan dasar matematika sejak awal sehingga kemampuan anak pada mata pelajaran matematika dapat meningkat.

Pada dasarnya kesalahan-kesalahan yang sering dilakukan siswa dalam menghadapi soal matematika adalah yang pertama menentukan hal yang diketahui dan ditanya, terkadang siswa kurang memahami apa maksud soal sehingga tidak mengetahui apa saja yang diketahui dan apa yang ditanyakan. Kedua siswa kesulitan menentukan model matematika dari permasalahan yang ada (Rosyidi 2015). Dalam menyelesaikan masalah kontekstual atau pun masalah matematika dalam bentuk cerita, siswa harus membuat menjadi model matematika agar lebih mudah diselesaikan, namun siswa sering membuat kesalahan dalam prosesnya seperti salah mendefinisikan variabelnya, salah membuat persamaannya, dan sebagainya. Ketiga siswa sering membuat kesalahan dalam melakukan perhitungan, dan yang terakhir siswa sering salah menulis jawaban akhir akibat dari kurangnya memahami makna soal. Kesalahan-kesalahan seperti ini jugalah yang sering dirasakan oleh siswa-siswi di SMPK Tunas Bangsa. Berdasarkan hasil wawancara dengan beberapa guru dan siswa di SMPK Tunas Bangsa, siswa sangat sulit untuk memahami pelajaran ini terutama terkait konsep aljabar dan geometri karena merasa materi ini tidak menarik dan membosankan karena kerjaannya hanya hitung-hitungan saja, akibatnya para siswa menjadi tidak suka dengan pelajaran matematika khususnya terkait materi konsep aljabar dan geometri. Hal inilah yang menjadi dasar banyaknya siswa-siswi tidak menyukai pelajaran matematika.

Salah satu upaya yang dapat ditempuh agar kita dapat menanam dasar matematika pada anak-anak khususnya siswasiswi SMPK Tunas Bangsa adalah dengan menggunakan metode belajar yang lebih menarik, sehingga siswa akan lebih tertarik dan semangat dalam belajar matematika khususnya untuk konsep aljabar dan geometri bidang matematika, dari ketertarikan siswa inilah yang akan membuat siswa lebih fokus dan lebih memahami apa yang diajarkan, dan dengan memberikan contoh masalah kontekstual, siswa akan lebih bisa memahami materi yang disajikan. Di antaranya adalah menggunakan mathmagic di dalam pembelajaran matematika aljabar. Menurut Marbun dkk (2019), dalam proses pembelajaran, metode mathmagic akan meningkatkan rasa percaya diri anak, sehingga mereka akan mampu dan berani untuk mengerjakan soal dan mencoba untuk menyelesaikannya.

Dengan mathmagic, pengerjaan hitungan dasar akan menjadi jauh lebih mudah dan sederhana sehingga akan tertanam suatu kesan awal bahwa matematika itu mudah dan menyenangkan. Kelebihan belajar mathmagic: 1) Tidak diperlukan alat bantu apapun, kecuali alat tulis menulis, itupun jika diperlukan, dan strategi yang tepat, 2) Dapat digunakan oleh siapa saja, baik anak yang tidak suka (tidak berbakat) maupun yang suka (berbakat) matematika, dan 3) Rasa percaya diri sang anak akan bertambah setelah sang anak mengetahui cara penggunaannya sehingga akan berkorelasi positif terhadap pelajaran matematika di sekolahnya. Bahkan berkorelasi positif juga untuk mata pelajaran lain (Irawan \& Febrianti 2016).

Selanjutnya, untuk materi geometri, diajarkan pemahaman tentang cara mendapatkan rumus-rumus terkait bidang geometri melalui penjabaran-penjabaran menggunakan animasi, sehingga akan lebih mudah dipahami oleh para siswa. Menurut Reid \& Reid (2017), guru yang tidak memahami suatu konsep dengan baik akan mengalami kesulitan dalam menjelaskan konsep-konsep tersebut, memodelkannya, membangun koneksi antar konsep yang melibatkan konsep tersebut. Sehingga pada kegiatan pengabdian ini, selain memberikan materi pengajaran yang menarik pada siswa, juga memberikan penguatan konsep-konsep dasar pada guru sehingga guru tidak hanya memberikan rumusrumus saja untuk diingat oleh siswa melainkan menjelaskan pula cara mendapatkannya. 


\section{Metode}

Pengabdian kepada Masyarakat (PKM) ini dilakukan dengan memberikan materi dengan selingan permainan matematika di antaranya mathmagic dan juga diberikan motivasi-motivasi agar siswa-siswi lebih tertarik dalam belajar matematika.

Kegiatan PKM ini dilaksanakan secara daring melalui aplikasi zoom dengan peserta merupakan siswa-siswi SMPK Tunas Bangsa Kota Kupang, Nusa Tenggara Timur. Langkah-langkah yang dilaksanakan untuk mencapai hasil tema PKM adalah: 1) Memberikan materi aljabar melalui mathmagic. 2) Memberi kesempatan kepada siswa-siswi untuk mempraktekkan mathmagic yang sudah dipelajari. 3) Memberikan materi geometri melalui animasi khususnya untuk materi bangun datar. 4) Memberikan motivasi pada siswa agar tertarik belajar matematika.

\section{Hasil dan Pembahasan}

Hasil yang dicapai dari kegiatan PKM ini adalah pemberian penguatan konsep aljabar dan geometri kepada siswasiswi SMP Kristen Tunas Bangsa Kota Kupang dengan metode yang menarik, yaitu dengan memberikan materi aljabar dalam bentuk permainan sulap matematika dan simulasi menggunakan gambar-gambar untuk mendapatkan rumus-rumus luas bidang datar di antaranya persegi panjang, segitiga, jajargenjang, trapesium, belah ketupat, dan lingkaran.

Dalam kegiatan ini, guru-guru matematika SMP Kristen Tunas Bangsa pun ikut berpartisipasi. Dengan berpartisipasinya guru-guru, harapannya dalam memberikan materi pelajaran selanjutnya, guru-guru dapat meniru dan juga berkreasi untuk dapat membuat pelajaran matematika yang akan diberikan membuat siswa-siswi tertarik untuk belajar matematika.

Tahap awal dalam kegiatan ini adalah permohonan izin dilanjutkan dengan penentuan waktu para siswa dan guru. Setelah itu, dilakukan diskusi Bersama guru-guru untuk penentuan materi yang akan disampaikan, agar materi yang diberikan nanti masih berkaitan dengan kurikulum yang sedang digunakan sekolah SMP Kristen Tunas Bangsa.

Dalam pelaksanaannya, pertama diawali dengan memberi motivasi kepada siswa-siswi dalam bentuk permainan agar siswa-siswi tertarik dalam mengikuti materi yang diberikan. Selanjutnya diberikan materi mengenai sulap matematika menggunakan aljabar. Dalam materi ini, diberikan dahulu materi-materi dasar terkait aljabar yang akan digunakan dalam sulap matematika, setelah itu pemateri mempraktekkan sulap matematika kepada siswa-siswi, dan terakhir pemateri memberikan trik dari sulap tersebut kepada siswa-siswi sehingga mereka juga dapat mempraktekkannya dan juga dapat berkreasi sendiri membuat sulapnya dengan menggunakan aljabar. Para peserta cukup aktif dalam memberikan tanggapan-tanggapan selama pemberian materi aljabar ini, sehingga kegiatan tidak terlihat membosankan dan monoton, sehingga bisa dikatakan bahwa peserta cukup menikmati dalam proses pemberian materi pertama ini, terutama saat diberi permainan-permainan, baik itu permainan untuk motivasi dan permainan sulap matematika. Hal ini sejalan dengan pendapat Siregar \& Surya (2017), yang mengatakan bahwa motivasi belajar siswa akan mengalami peningkatan setelah diberikan perlakuan dengan menerapkan metode mathmagic, atau dengan kata lain metode mathmagic efektif digunakan pada pelajaran matematika.

Materi kedua yang diberikan adalah materi terkait geometri yang disajikan dalam bentuk simulasi menggunakan gambar-gambar untuk mendapatkan rumus-rumus luas bidang datar, di antaranya persegi panjang, segitiga, jajargenjang, trapesium, belah ketupat, dan lingkaran. Dalam materi ini, siswa-siswi diberikan pemahaman bagaimana mendapatkan rumus-rumus luas bangun datar yang selama ini mereka gunakan. Materi diberikan dalam bentuk simulasi sehingga sangat mudah untuk dipamahami oleh siswa-siswi. Dari materi ini, diharapkan juga para guru nantinya dapat menggunakan materi serupa untuk menjelaskan materi-materi terkait geometri sehingga anak-anak tidak hanya menghafal rumus, tetapi memahami konsep mendapatkan rumusnya. Dengan memahami konsepnya, maka jika diberikan masalah-masalah baru yang berkaitan, siswa juga dapat berkreasi untuk mencoba mendapatkan rumus yang diinginkan. 
Materi terakhir yang diberikan adalah motivasi dan materi tentang pentingnya matematika dalam kehidupan seharihari. Motivasi merupakan faktor paling penting bagi pendidik dalam mencapai target yang bertujuan untuk meningkatkan pembelajaran. Ada lima hal yang mempengaruhi motivasi siswa yaitu: siswa itu sendiri, guru/ pendidik, isi materi pelajaran, metode atau proses pembelajaran, serta lingkungan (Williams \& Williams 2011). Materi diberikan dengan memberikan contoh-contoh nyata dalam kehidupan sehari-hari, yang latar belakangnya semua menggunakan matematika. Dari materi ini, diharapan siswa-siswi tidak lagi berusaha untuk menghidari mempelajari matematika, sehingga di masa mendatang mereka tidak kesulitan pada masalah-masalah yang berhubungan dengan matematika.

Berikut adalah beberapa dokumentasi dari kegiatan ini:

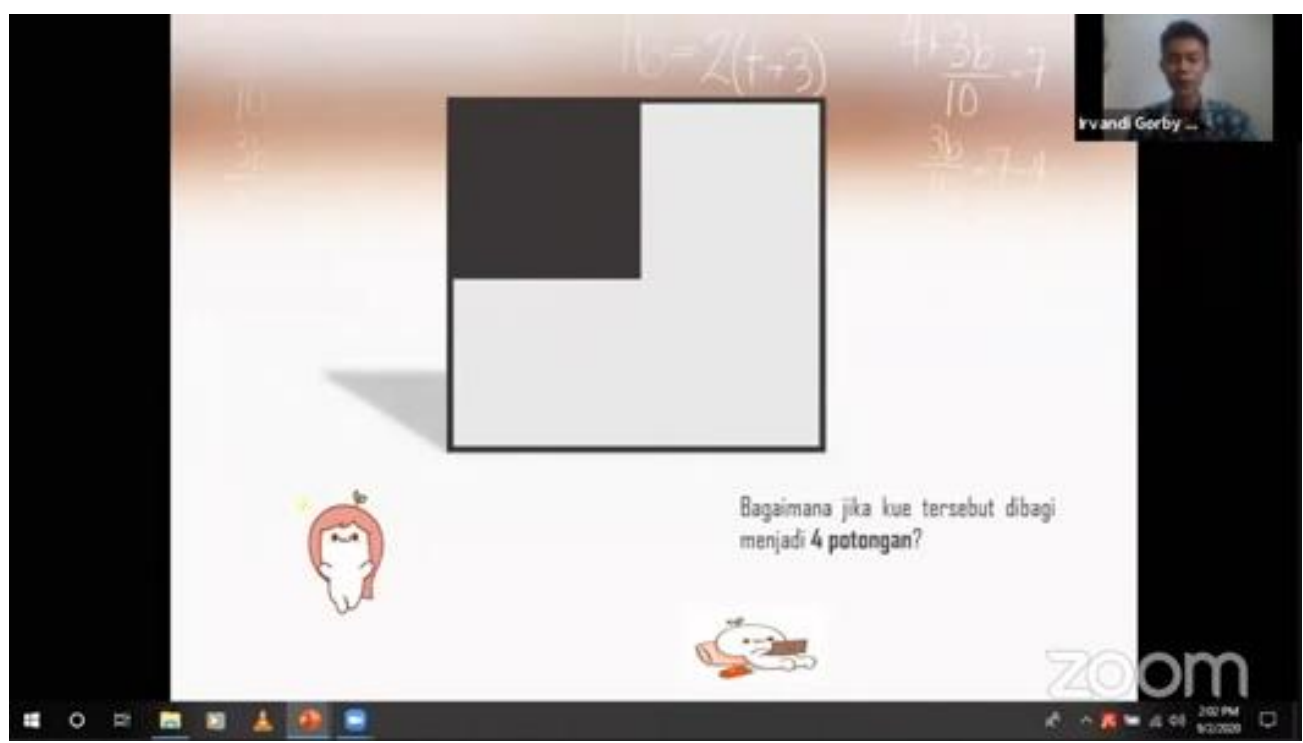

Fig. 1. Permainan terkait pemberian motivasi belajar matematika

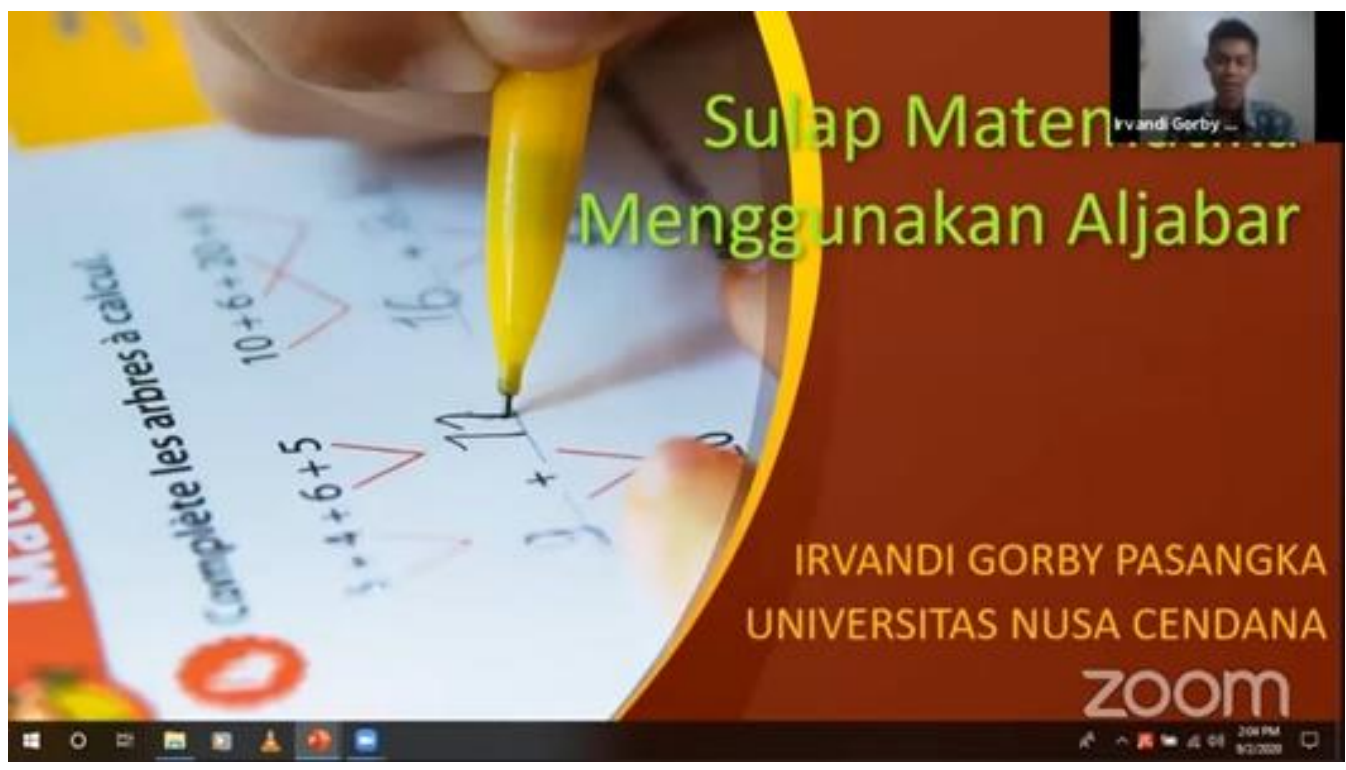

Fig. 2. Materi sulap matematika 


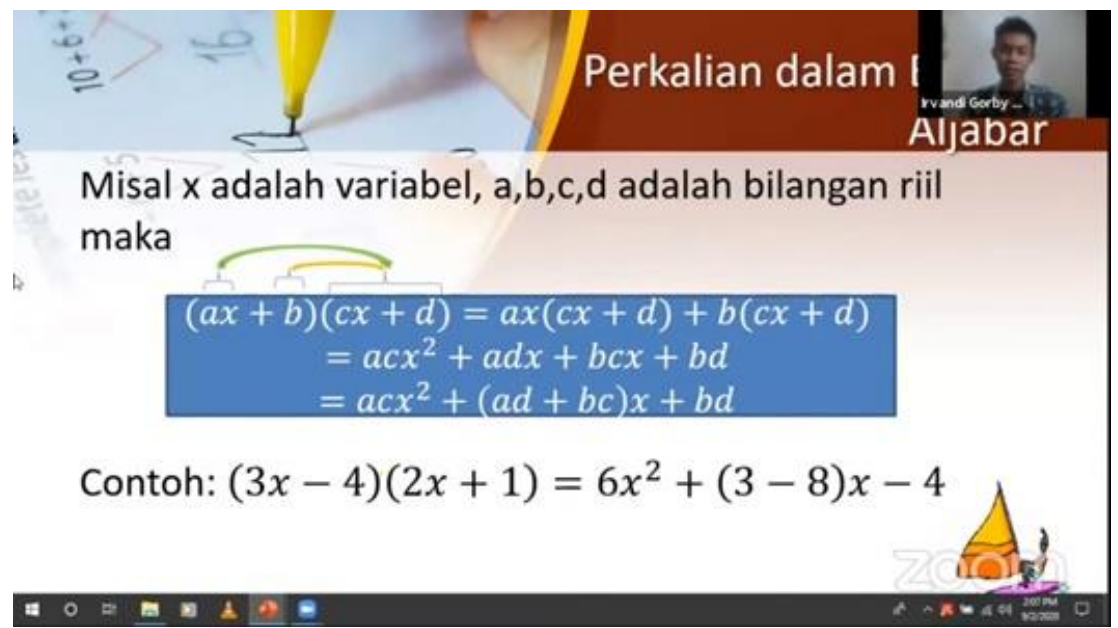

Fig. 3. Proses pemberian materi aljabar

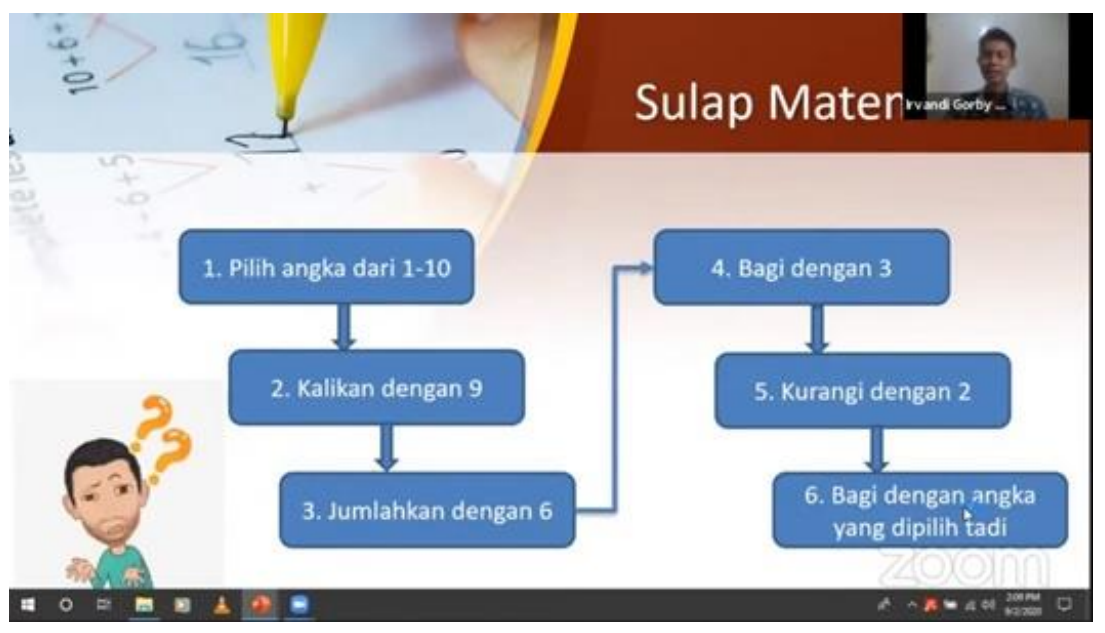

Fig. 4. Praktek sulap matematika

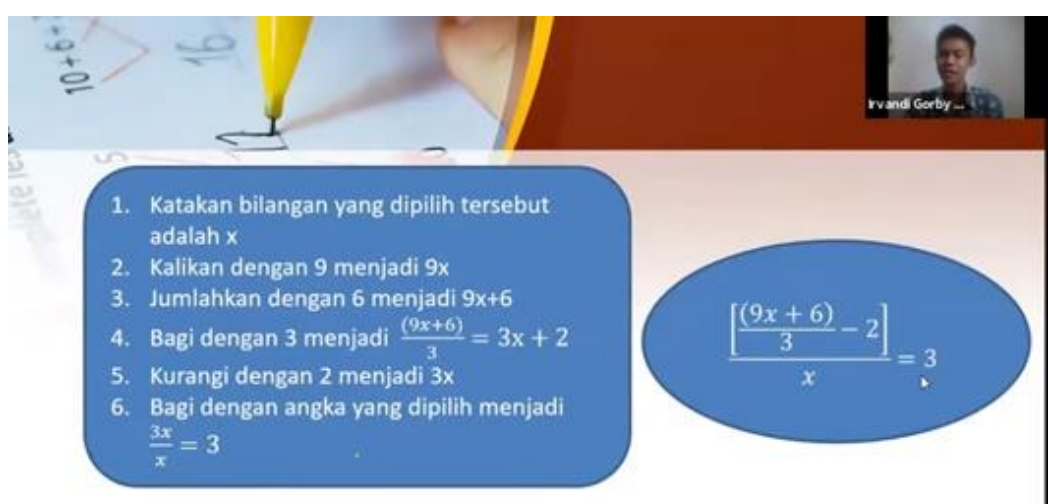

Fig. 5. Memberikan trik sulap matematika 
KETERKAITAN RUMUS LUAS ANTAR POL (BANGUN DATAR)

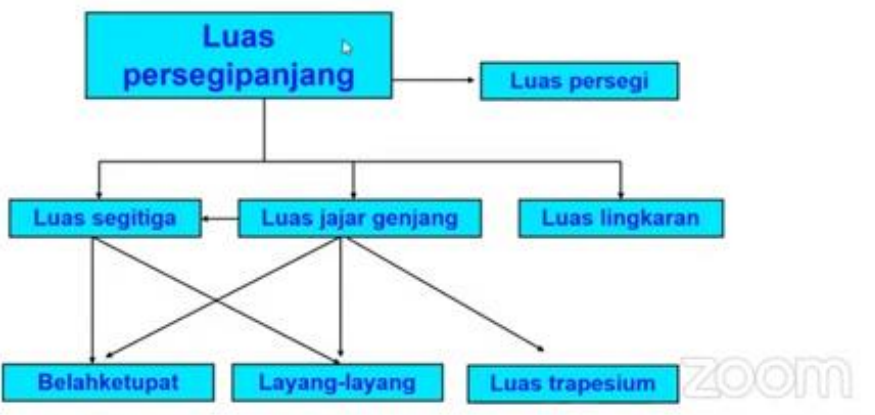

Fig. 6. Materi geometri

\section{LANGKAH-LANGKAH:}

1. Perhatikan persegipanjang dan perseg

satuan berikut!

2. Tutuplah persegipanjang tersebut denga

persegi satuan yang tersedia!

3. Berapa persegi satuan yang dapat

menutupi daerah persegipanjang tersebut?

4. Perhatikan lagi persegipanjang berikut!

5. Tutupilah sebagian persegipanjang

yang diwakili oleh bagian salah satu

$$
\text { kolom dan baris. }
$$

6. Dengan cara apa dapat menghitung luas

persegipanjang tersebut?

7. Jika banyak kolom adalah $p$ dan banyak

baris adalah $l$, maka dapat diperoleh

rumus luas persegipanjang adalah ...

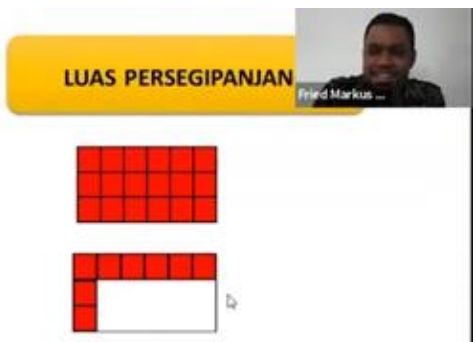

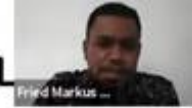

Prigdmones.

uas trapesium 


\section{LANGKAH-LANGKAH:}

1. Gambarlah dua buah trapesium siku siku yang konkruen!

2. Susun kedua trapesium tersebut sehingga benbentuk persegipanjang!
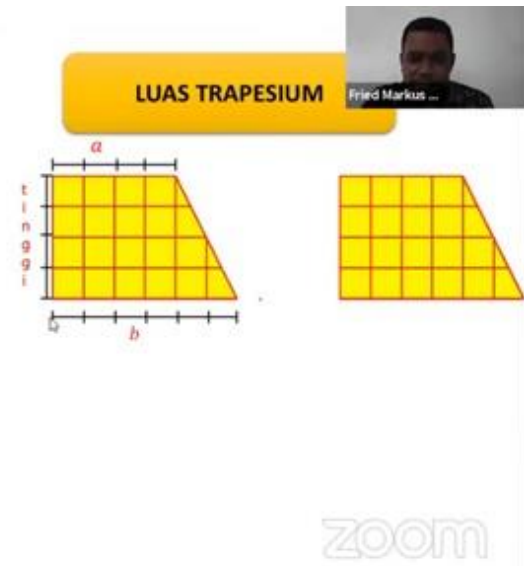

Fig. 9. Materi penentuan luas trapesium

13. Coba perhatikan jika lingkaran dibagi menjadi 32 juring sama besar dan disusun seperti langkah 6 !

14. Coba bandingkan hasil susunan petama dengan susunan kedua ketiga dan keempat, beri komentar !
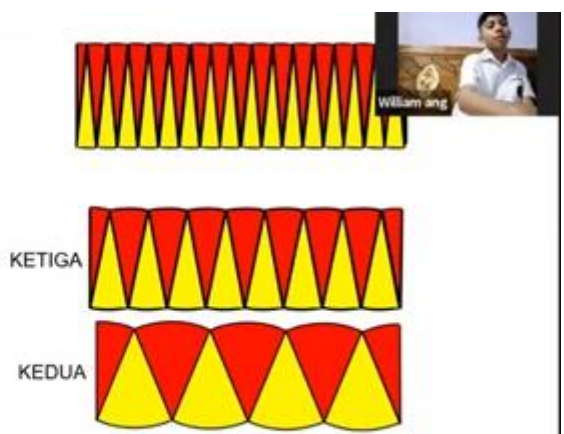

PERTAMA

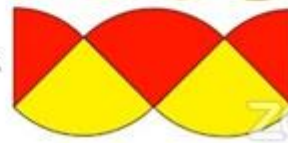

Fig. 10. Siswa memberi tanggapan pada materi yang diberikan

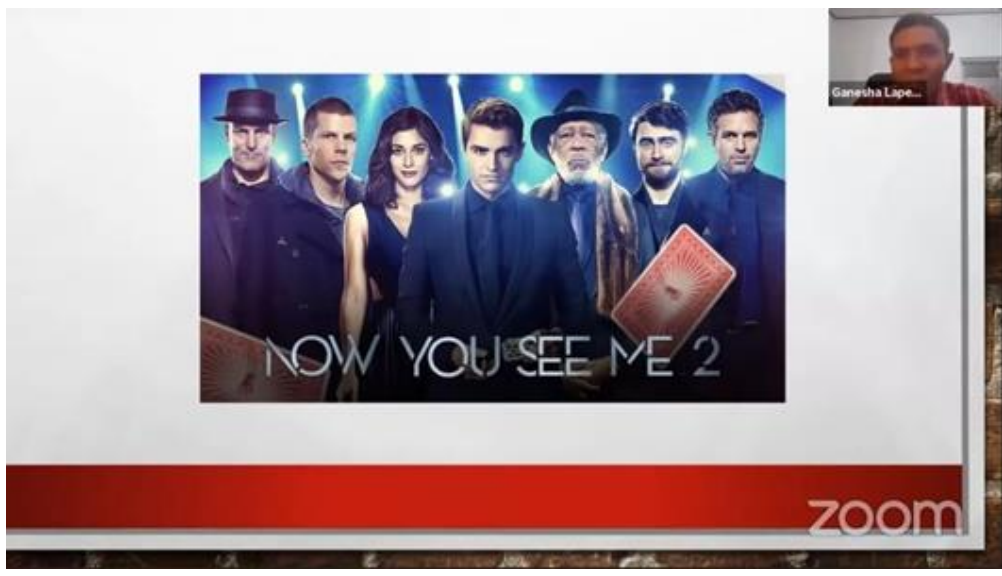

Fig. 11. Pemberian motivasi belajar matematika 


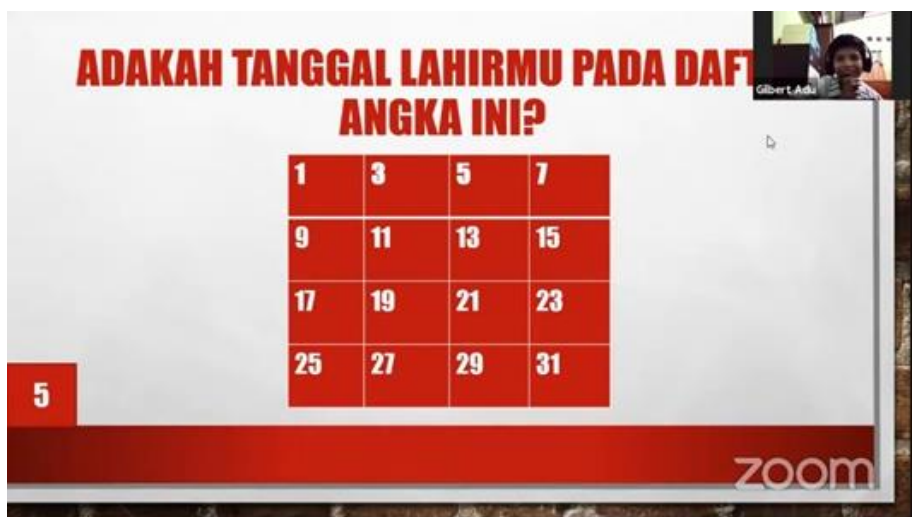

Fig. 12. Bermain game Bersama peserta

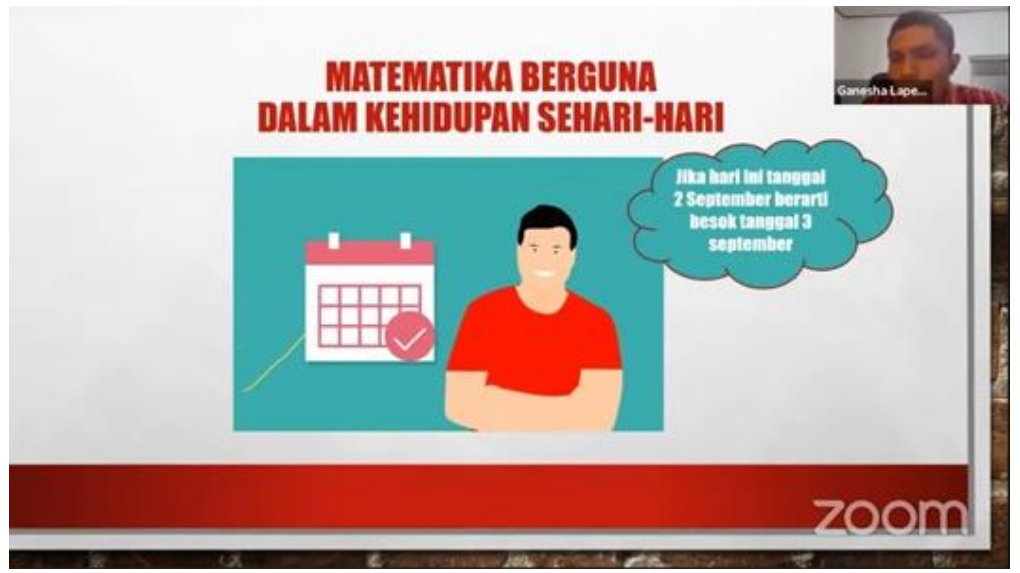

Fig. 13. Materi pentingnya belajar matematika

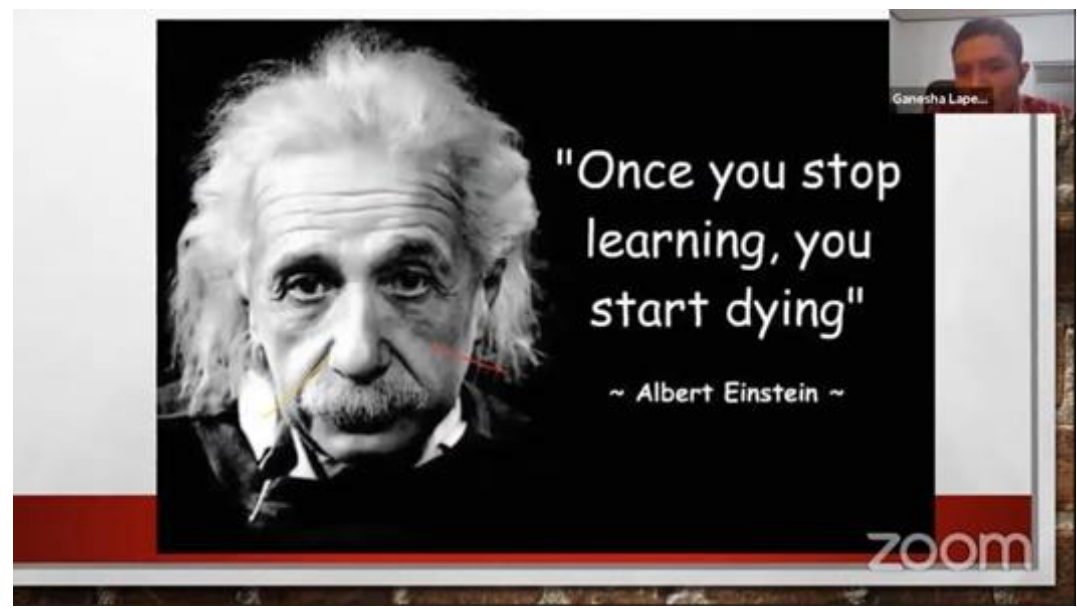

Fig. 14. Pemberian motivasi 


\section{Kesimpulan}

Berdasarkan hasil pelaksanaan kegiatan pengabdian yang telah dilakukan di SMP Kristen Tunas Bangsa Kota Kupang, maka dapat disimpulkan beberapa hal sebagai berikut:

1. Kegiatan PKM yang dilaksanakan pada SMP Kristen Tunas Bangsa Kota Kupang dapat berjalan dengan baik dan diikuti oleh kepala sekolah, guru-guru matematika, dan siswa-siswi kelas 7 dan 8 SMP Kristen Tunas Bangsa.

2. Para peserta cukup aktif dalam memberikan tanggapan-tanggapan selama kegiatan berlangsung, sehingga kegiatan tidak terlihat membosankan dan monoton.

3. Berdasarkan hasil tanya jawab yang dilakukan selama kegiatan berlangsung, dapat diketahui bahwa para peserta dapat menangkap apa yang disampaikan oleh para pemateri.

4. Peserta cukup menikmati dalam proses pemberian materi terutama saat diberi permainan-permainan, baik itu permainan untuk motivasi dan permainan matematika.

5. Para guru yang mengikuti kegiatan sangat tertarik dengan materi yang diberikan dan ingin mempraktekkannya dalam pembelajaran di kelas khususnya untuk pelajaran matematika.

\section{Acknowledgements}

Penulis mengucapkan terima kasih kepada pihak Universitas Nusa Cendana yang telah memberi dukungan financial terhadap pengabdian ini.

\section{References}

As'ari, A. R., dkk. (2017). Buku Guru Matematika, Kementerian Pendidikan dan Kebudayaan Republik Indonesia.

Irawan, Ari., \& Febrianti, C. (2016). Efektifitas Mathmagic dalam Peningkatan Hasil Belajar Matematika. Jurnal Formatif 6(1): 85-92, 2016.

Koirala, H. P., \& Goodwin, P. M. (2000). Teaching algebra in the middle grades using math magic. Mathematics Teaching in the Middle School, 5(9), 562-566.

Kurniawan, D., \& Wustqa, D. U. (2014). Pengaruh perhatian orangtua, motivasi belajar, dan lingkungan sosial terhadap prestasi belajar matematika siswa SMP. Jurnal Riset Pendidikan Matematika, 1(2), 176-187.

Marbun, N. E., dkk (2019). Pengaruh Mathmagic dengan Model Pembelajaran Scramble Terhadap Hasil Belajar Siswa. MES: Journal of Mathematics Education and Science, Vol. 5, No. 1.

Nasaruddin, N. (2018). Media dan Alat Peraga dalam Pembelajaran Matematika. Al-Khwarizmi: Jurnal Pendidikan Matematika dan Ilmu Pengetahuan Alam, 3(2), 21-30.

Reid, M., \& Reid, S. (2017). Learning to be a math teacher: What knowledge is essential? International Electronic Journal of Elementary Education, 9(4), 851-872.

Rosyidi, A. H. (2015). Analisis Kesalahan Siswa Kelas II MTs Al-Khoiriyah dalam Menyelesaikan Soal Cerita yang Berkaitan SPLDV, Surabaya: Tesis UNESA.

Siregar, N. D., \& Surya, E. (2017). Penggunaan Mathmagic dalam Meningkatkan Motivasi Belajar Siswa. Kreano: Jurnal Matematika Kreatif -inovatif 8(1): 46-52.

Sriyanto, H.J. (2009). Bermain Sulap dengan Matematika: Cara Asyik Bermain Angka, Indonesia Cerdas, Yogyakarta. 
Susanti, D., dkk. (2020). Peningkatan Kompetensi Guru SMP dalam Pembuatan dan Penerapan Bahan Manipulatif Matematika. Jurnal Pengabdian Masyarakat Borneo, Vol. 4, No. 1, 65-72.

Williams, K. C., \& Williams, C. C. (2011). Five key ingredients for improving student motivation. Research in Higher ducation Journal, 12, 1.

Yensy, N. (2012). Penerapan Model Pembelajaran Kooperatif Tipe Examples Non Examples dengan Menggunakan Alat Peraga Untuk Meningkatkan Hasil Belajar Siswa di Kelas Viii SMPN 1 Argamakmur. Exacta, 10(1), $24-35$. 